\title{
Análise Ergonômica do Trabalho (AET) no ambiente de escritório: Um estudo de caso em uma empresa na cidade de Manaus-AM
}

\author{
Ergonomic Work Analysis (AET) in the office environment: A case study in a company in the city \\ of Manaus-AM
}

Análisis ergonómico del trabajo (AET) en el entorno de oficina: Un caso de estudio en una empresa de la ciudad de Manaus-AM

Recebido: 25/05/2021 | Revisado: 03/06/2021 | Aceito: 18/06/2021 | Publicado: 02/07/2021

\author{
Keila Regina Alves Sampaio \\ ORCID: https://orcid.org/0000-0002-7741-0329 \\ Instituto de Ensino Superior Blauro Cardoso de Mattos, Brasil \\ E-mail: ksampaio1993@gmail.com \\ Valmir Batista \\ ORCID: https://orcid.org/0000-0002-1468-5966 \\ Instituto de Ensino Superior Blauro Cardoso de Mattos, Brasil \\ E-mail: batista-engenharia2013@hotmail.com
}

\begin{abstract}
Resumo
Conhecida como a ciência que relaciona o homem aos seus ambientes de trabalho, a ergonomia se faz cada vez mais necessária às empresas e aos seus colaboradores. Uma vez que, possibilita resultados e um amplo conhecimento dividido entre seus domínios caracterizando a aplicação de métodos regidos pela norma regulamentadora 17. Deste modo, o objetivo deste estudo de caso é mostrar a real importância da ergonomia no ambiente de trabalho em escritório, ao qual é atribuído tarefas que causam impacto no aspecto físico e psicossocial dos colaboradores. Dessa forma será apresentada uma breve revisão literária sobre a ergonomia; áreas da ergonomia e análise ergonômica. Metodologia, é um estudo de natureza quantitativa. Resultados obtidos: A maioria dos colaboradores da empresa apresentam irregularidades no domínio postural, esses dados representam a quantidade de irregularidades pelo número de postos. Em relação ao risco à saúde psicossocial, o apoio social e qualidade de liderança é o problema mais comum dentre os departamentos do setor da empresa, com cerca de trinta e quatro colaboradores afetados.
\end{abstract}

Palavras-chave: Ergonomia; Riscos psicossociais; Escritório.

\begin{abstract}
Known as the science that relates man to his work environments, ergonomics is increasingly necessary for companies and their employees. Since, it allows results and a wide knowledge divided among its domains, characterizing the application of methods governed by the regulatory norm 17. Thus, the objective of this case study is to show the real importance of ergonomics in the office work environment, whose tasks are assigned that impact the physical and psychosocial aspect of employees. In this way, a brief literary review on ergonomics will be presented; areas of ergonomics and ergonomic analysis. Methodology, is a study of quantitative nature. Results obtained: Most of the company's employees have irregularities in the postural domain, these data represent the number of irregularities by the number of posts. In relation to psychosocial health risk, social support and the quality of leadership is the most common problem among areas of the company sector, with around thirty-four employees affected.
\end{abstract}

Keywords: Ergonomics; Psychosocial risks; Writing desk.

\section{Resumen}

Conocida como la ciencia que relaciona al hombre con sus entornos laborales, la ergonomía es cada vez más necesaria para las empresas y sus empleados. Ya que, permite resultados y un amplio conocimiento repartido entre sus dominios, caracterizando la aplicación de métodos regidos por la norma reglamentaria 17. Así, el objetivo de este caso de estudio es mostrar la importancia real de la ergonomía en el entorno de trabajo de oficina, cuyas tareas son asignados que impactan el aspecto físico y psicosocial de los empleados. De esta forma, se presentará una breve reseña literaria sobre ergonomía; áreas de ergonomía y análisis ergonómico. Metodología, es un estudio de carácter cuantitativo. Resultados obtenidos: La mayoría de los empleados de la empresa tienen irregularidades en el dominio postural, estos datos representan el número de irregularidades por el número de puestos. En relación al riesgo psicosocial para la salud, el apoyo social y la calidad del 
liderazgo es el problema más común entre las áreas del sector empresarial, con alrededor de treinta y cuatro empleados afectados.

Palabras clave: Ergonomía; Riesgos psicosociales; Escritorio.

\section{Introdução}

A saúde e o bem-estar dos colaboradores são essenciais ao bom desempenho de suas atividades cotidianas, vale ressaltar que uma empresa que está em constante desenvolvimento, precisa se adequar adotando práticas que ajudem a prevenir doenças ocupacionais e acidentes de trabalho, tendo em vista, o impacto direto na qualidade de vida, na saúde e na produtividade dos trabalhadores. Sendo assim, ao se discutir esta vertente, vem à tona a ergonomia.

De acordo com Ferreira et al. (2017) "a ergonomia é a ciência do trabalho que estuda as intervenções entre os seres humanos e outros elementos do sistema, aplicando teorias, princípios, dados e métodos a projetos que busquem otimizar o bemestar humano e o desempenho global de sistemas". Ou seja, ela busca entender e melhorar a relação do homem com o trabalho, estabelecendo normas que beneficie tanto a empresa quanto o funcionário.

Dessa forma, o estudo desta ciência é adquirido através da análise ergonômica do trabalho (AET), que segundo Martins (2017), "possibilita a identificação, diagnóstico e elaboração de medidas para a resolução dos problemas ergonômicos que afetam a saúde e o desempenho do trabalho humano." Visto que, existe muitos trabalhadores que se afastam por doenças ocupacionais causadas pela forma que exercem suas atividades diárias.

Iida e Buarque (2016) afirma que, com o passar dos anos, as empresas estão cada vez mais empenhadas em implantar programas que contribuam para a saúde do trabalhador, desenvolvendo projetos e estudos ergonômicos que visam contribuir com suas vantagens de maneira eficaz na qualidade de vida dos funcionários, e consequentemente alavancar a produtividade.

"Esta ciência possui três domínios de especialização: física, cognitiva e organizacional [...]” Ferreira et al. (2017, p. 3). Ao qual observam diferentes aspectos que ajudam na classificação de medidas normativas que auxiliam no processo de redução de riscos no ambiente de trabalho.

O presente artigo contribui no levantamento da análise de questões relacionadas ao ambiente de escritório, assim como suas condições físicas e aspectos cognitivos. Sempre em conformidade com a legislação específica que abrange as áreas da ergonomia, norma regulamentadora - NR17, pertencente ao Ministério do Trabalho e Emprego - MTE.

O estudo de caso, dispõe-se a realizar uma avaliação das condições ergonômicas dos postos de trabalho e o risco psicossocial dentro do ambiente de escritório, e a partir dessa análise, sugerir melhorias ao setor com medidas preventivas para a otimização do ambiente de trabalho e qualidade de vida dos colaboradores.

Diante do exposto, levantou-se o seguinte questionamento: Como se configura as condições ergonômicas em empresas no ambiente de escritório? Há alguma relação entre a não adequação de índole ergonômica física e os fatores de riscos psicossociais?

Com isso, o presente estudo tem como objetivo geral mostrar a real importância da ergonomia no ambiente de trabalho, ao qual é atribuído tarefas que causam impacto no aspecto físico e psicossocial dos colaboradores.

Objetivo específico: responder aos questionamentos levantados no âmbito de estudo de caso, apresentando resultados de uma análise ergonômica focada na área física e psicossocial do setor de uma empresa situada na cidade de Manaus, ao qual suas atividades são realizadas por colaboradores em um ambiente de escritório, pretende-se ainda com este estudo, levantar dados pertinentes ao tema da pesquisa, observando seus meios de trabalho, métodos e procedimentos.

\section{Metodologia}

O estudo apresentado é desenvolvido inicialmente com a abordagem qualitativa, ao qual se trata de um estudo de caso, 
através da revisão de literatura para obter fundamentos a investigação. Os dados foram coletados em livros, sites eletrônicos e artigos já publicados em revista, disponibilizados na plataforma de pesquisa Google acadêmico e Researchgate, utilizando as palavras chaves (Ergonomia. Riscos psicossociais. Escritório) no período de 2016 a 2021. Além disso, o presente estudo de caso foi desenvolvido obedecendo as seguintes etapas: elaboração do tema, a fundação dos padrões de elegibilidade, observação das publicações em sites e plataformas de buscas, análises dos dados pertinentes ao estudo e apresentação dos resultados, Pereira et al. (2018). Como critérios de inclusão no estudo apresentado, foram inseridos os artigos mais adequados aos objetivos destacados neste estudo de caso.

Em seguida o trabalho propriamente dito foi elaborado em natureza quantitativa, na qual se preocupou em responder aos questionamentos abordados no início do trabalho. Com referência a este meio de pesquisa, Oliveira (2017) comenta que, a abordagem quantitativa usa técnicas estatísticas de forma intensiva, relacionando os aspectos e analisando o impacto e a validade do experimento e essas técnicas devem ser adequadas ao tipo de delineamento adotado.

Para isso, foi feita a coleta de informações a partir da pesquisa quantitativa por meio eletrônico, da qual pode-se criar, implantar e acompanhar através da utilização da ferramenta Google Forms um questionário ao qual foi enviado a todos os colaboradores do setor da empresa. Neste caso, a pesquisa foi aplicada de forma facultativa e anônima, para que os trabalhadores que se dispusessem a respondê-la, a fizessem com sinceridade. Posteriormente, após a pesquisa, foi realizada uma inspeção nos postos de trabalho para o efetivo preenchimento do questionário relacionado a postura, aos equipamentos e as condições ambientais. Os instrumentos utilizados foram a Check list de Lima e Coelho (2011) e o Questionário Psicossocial de Copenhaga: ISTAS 21 (CoPsoQ) - versão curta.

\subsection{Cheklist}

"O Check list tem por base avaliar o domínio postural de sentar, do equipamento e as condições ambientais do posto de trabalho em escritório [...]" Tavares (2012) citado por Brochier at al (2018).

Sendo assim, este questionário é dividido em quatro listas para verificação de resultados, tais definidos como: domínio postural; domínio de sentar-se; domínio do equipamento no posto de trabalho; layout e condições ambientais. Tavares (2012) citado por Brochier at al (2018).

Será realizada uma avaliação ergonômica no ambiente de escritório por meio do preenchimento do checklist através de uma inspeção em campo, com o objetivo de avaliar estrategicamente os postos de trabalho de forma específica e eficaz.

A Check list se classifica em quatro fases, possibilitando a avaliação do máximo de itens, com vista a obter uma melhor avaliação dos postos de trabalho.

O resultado será obtido através da pontuação e será apresentado por meio de gráficos estatísticos ao qual diz respeito ao número de postos que estão inadequados e quantos têm cada um em sua índole ergonômica.

\subsection{ISTAS 21 (CoPsoQ)}

O CoPsoQ se configura "não apenas em ser um instrumento de avaliação e monitorização dos fatores de risco psicossocial, mas também contribuir melhor compreensão de conceitos e teorias múltiplos e complexos no domínio dos fatores de risco psicossociais no trabalho [...]" Patrone et al. (2017).

O questionário ISTAS 21 (CoPsoQ) é dividido em seis etapas: "Exigências Psicológicas; Trabalho ativo e possibilidade de desenvolvimento; Insegurança; Apoio social e qualidade de liderança; Conflito trabalho/família; Autoestima” Tavares (2012) citado por Brochier at al (2018).

Em seguida, e após a coleta de dados informativos, estes foram enviados e estudados estatisticamente através da ferramenta Google Forms. Por fim, após a filtração e organização dos diversos resultados, avançou-se à fase de interpretação e discussão dos mesmos, o que permitiu apresentar conclusões relevantes a este trabalho. 


\section{Revisão de literatura}

\subsection{Ergonomia}

A ergonomia é um conceito bastante introduzido em vários seguimentos de empresas em todo o mundo, seu papel é bastante relevante por ter como princípio a integridade no ambiente de trabalho e relação entre o trabalhador e a empresa.

"A palavra ergonomia é proposta pelas palavras gregas ergon (trabalho) e nomos (leis e regras). Esse termo foi adotado pela primeira vez em 1857, por um cientista polonês, WoJciech Jastrzebowski, em um trabalho intitulado "Ensaios de Ergonomia" [...]" Abrahão et al. (2009). Na qual foi definida como a relação entre os trabalhadores e a forma como os mesmos executam suas atividades cotidianas no ambiente de trabalho.

Segundo Silva (2018) a ergonomia avalia diferentes aspectos na qual envolvem a postura, os equipamentos utilizados nos postos de trabalho, assim como também os fatores ambientais e físicos. $\mathrm{O}$ autor diz ainda que, a ergonomia busca realizar uma boa integração entre a capacidade e a limitação, bem como sua condição e eficiência na produtividade.

\section{2 Áreas da Ergonomia}

A ergonomia aborda trabalhos que incorporam diferentes aspectos, tais foram definidos pela Associação Internacional de Ergonomia, que a divide em três áreas. São elas:

\section{- Ergonomia física}

Segundo Soares et al. (2016) "trata da relação das características anatômicas, antropométricas, fisiológicas e biomecânicas do homem com a atividade física realizada, envolvendo, por exemplo, o estudo do posto de trabalho, posturas, repetitividade, layout, entre outros.” Ou seja, este tipo de ergonomia se entende pelas respostas que são definidas do corpo humano em relação a carga física e psicológica.

"A Ergonomia física visa um equilíbrio entre as exigências do trabalho aos limites e capacidades do homem. Com as exigências do mundo moderno, as empresas buscam por uma produtividade cada vez maior, para que consigam atingir a demanda do mercado, e com isso as pessoas vêm se lamentando em desenvolverem tarefas repetitivas, posturas desfavoráveis e força excessiva” Abergo (2014) citado por Coimbra et al. (2017). Dessa forma, as exigências desse domínio estão ligadas ao processo repetitivo, pressão mecânica localizada, esforço físico, força e postura.

Entretanto Frota (2016) afirma que "no que tange às capacidades humanas e o confronto com as mais diversas exigências físicas no transcorrer dos diferentes postos de trabalho, cada uma com sua particularidade, podem trazer consequências gravíssimas ao trabalhador e a empresa empregadora". Ou seja, o trabalhador adquire doenças ocupacionais que dificultam sua performasse na rotina de trabalho e a empresa acaba sendo prejudicada por comprometer sua produtividade.

\section{- Ergonomia cognitiva}

De acordo com Quarto et al. (2019) "a ergonomia cognitiva se preocupa com o esforço mental exigido para a execução de uma tarefa. Ela busca minimizar as cargas psíquicas de trabalho, tornando o ambiente laboral mais agradável e menos ocioso". Dessa forma, a ergonomia é importante na vida do trabalhador por lidar com os pactos mentais relacionados a percepção, cognação, recuperação de memória e armazenamento.

"Assim, são parte da ergonomia cognitiva tópicos como os que envolvem o estudo da carga mental de trabalho, tomada de decisão, desempenho especializado, interação homem computador, estresse e treinamento relacionados ao homem e sistemas" Barddal (2016). Com isso, é notório que a ergonomia cognitiva abrange os processos mentais definidos na memória, no raciocínio, na percepção e na resposta motora entre o homem e os outros elementos do sistema.

Segundo Velasco (2018) “é uma área de interesse multidisciplinar que abrange a psicologia cognitiva, a psicobiologia, 
a filosofia, a antropologia, a linguística e a inteligência artificial, como um meio de melhor compreender como as pessoas percebem, aprendem, recordam e ponderam a informação". Ou seja, aos que se empenham no estudo cognitivismo, acreditam que a forma como as pessoas pensam implicará em uma ampla compreensão sobre boa parte do comportamento humano.

\section{- Ergonomia Organizacional}

Figueiredo e Díaz-Merino (2017) afirmam que "a ergonomia organizacional visa à otimização dos sistemas sociotécnicos, incluindo as estruturas organizacionais, políticas ou regras, e processos". Ou seja, essa área da ergonomia se preocupa com o trabalho em equipe, satisfação no trabalho, trabalhos em turnos, trabalho à distância, programação de trabalho, teoria motivacional, ética e supervisão.

De acordo com Wolf et al. (2020) "a ergonomia organizacional está relacionada ao aperfeiçoamento de sistemas e estruturas organizacionais com foco centrado no ser humano, incluindo-se estudos de projeto do trabalho, trabalho em grupo, comunicação interna, política e a cultura organizacional”. Dessa forma, o estudo sobre esta vertente, trata dos aspectos importantes ao desenvolvimento na relação dos trabalhadores em suas atividades com a empresa na qual atuam.

Segundo Silva (2018) "a ergonomia organizacional visa a redução de problemas internos, dentro do ambiente empresarial, causados por um ambiente de trabalho conflituoso. O trabalho deve ser fator de motivação dos funcionários, e o clima e a cultura existentes na empresa influenciam diretamente neste sentimento [...]". Sendo assim, a empresa deve ter mais atenção nesses aspectos, pois alguns conflitos podem impactar na gestão de forma negativa.

\subsection{Análise Ergonômica}

De acordo com Ferreira (2015) citado por Bastos et al. (2017) o termo, análise ergonômica do Trabalho ou AET, surgiu a partir da publicação de uma nova versão da norma regulamentadora de ergonomia 17 que aconteceu por volta dos anos 90, da qual lida com os domínios da segurança e saúde no ambiente de trabalho, estabelecendo assim o seguinte critério: "cabe aos empregadores realizar a análise ergonômica do trabalho". O autor diz ainda que a AET se caracteriza principalmente por ser um meio de estudo feito em campo, ou seja, baseado nos resultados obtidos em análise das atividades exercidas pelos colaboradores.

Iida (2005) citado por Corrêa (2017) afirma que, "a análise ergonômica do trabalho visa aplicar os conhecimentos da ergonomia para analisar, diagnosticar e corrigir uma situação real de trabalho". A autora diz ainda que, "esta análise exige a execução de algumas exigências, como iniciativas por parte da empresa e participação dos trabalhadores". E assim possibilitar o bom relacionamento entre trabalhador e empresa e a otimização na produtividade.

\section{Apresentação da organização}

A empresa escolhida para a elaboração deste artigo, é de direito privado, sendo assim seu nome não será mencionado. Está localizada na cidade de Manaus, e dentre os vários setores que ela possui, o Departamento (DCM) foi o escolhido para o desenvolvimento do estudo de caso. Seu setor se divide em três áreas: Triagem; Cálculo; Recurso e ADM. O Gráfico 1 mostra a quantidade percentual de colaboradores por área dentro setor. 
Gráfico 1: Dados do percentual quantitativo de funcionários no setor da empresa.

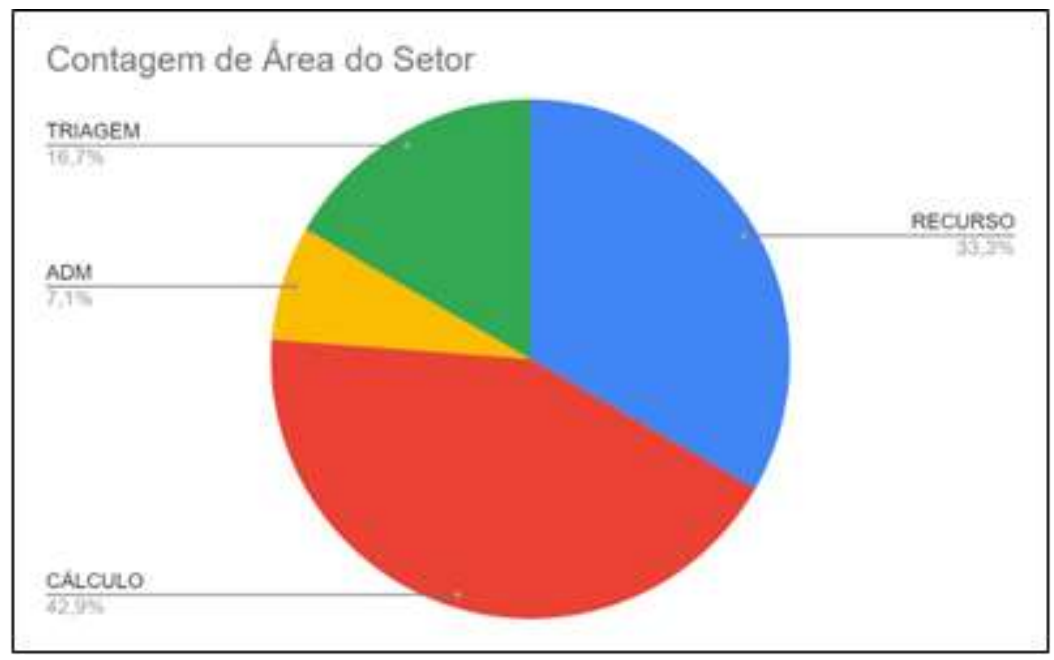

Fonte: Autores (2021).

O departamento possui apenas um horário de funcionamento, sendo das 7:30 às 17:30, e tem um total de colaboradores, dentre os quais vinte e oito do sexo feminino e vinte e dois são do sexo masculino. O Gráfico 2 mostra a quantidade em percentual dos colaboradores de ambos os sexos em todo o setor.

Gráfico 2: Dados da quantidade percentual por gênero no setor da empresa.

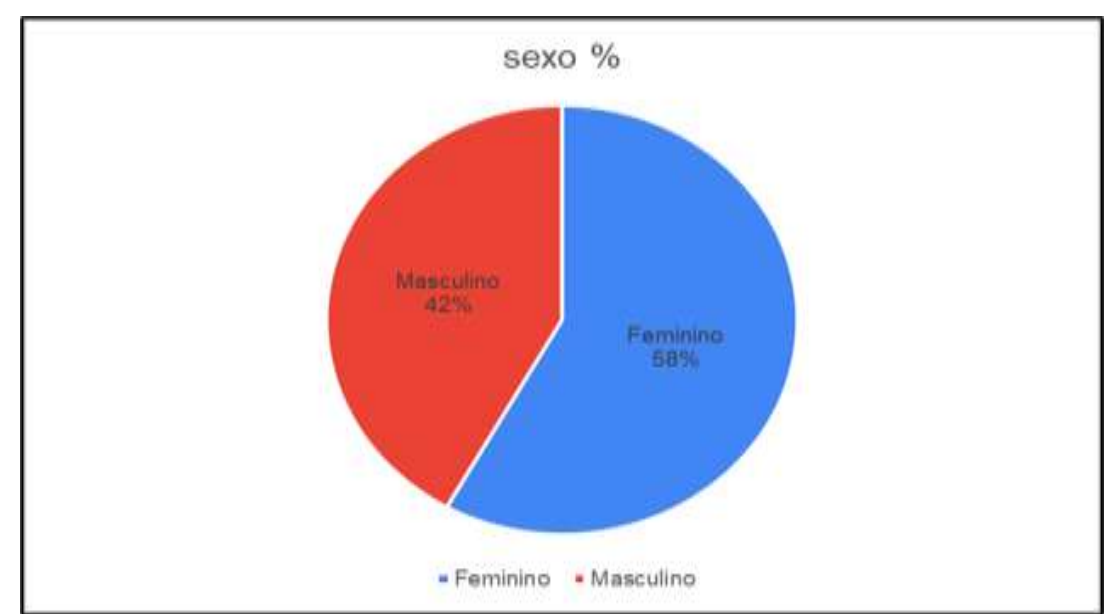

Fonte: Autores (2021).

\section{Resultados e Discussão}

Os resultados do estudo das duas pesquisas ao qual os trabalhadores da empresa foram submetidos, estão apresentados neste capítulo. No entanto, um desses questionários, apesar de ser respondido de forma anônima, por ter sido aplicado de forma facultativa, nem todos os colaboradores se dispuseram a responder, dessa forma, foram avaliados cerca de 42 funcionários em seus postos de trabalho dentre os departamentos estabelecidos dentro do setor.

\subsection{Resultado da avaliação do Risco Psicossocial}

Com base nas informações coletadas em pesquisa, pode-se observar por meio dos resultados em cada área do setor, onde é possível entender o nível de risco psicossocial ao qual os colaboradores estão sujeitados. 
O Gráfico 3 apresenta os resultados obtidos na pesquisa feita no departamento de Cálculo, onde pode-se analisar por meio dos dados coletados o nível de exposição psicossocial ao qual os colaboradores estão expostos.

Gráfico 3: Nível de Exposição Psicossocial na área do Cálculo.

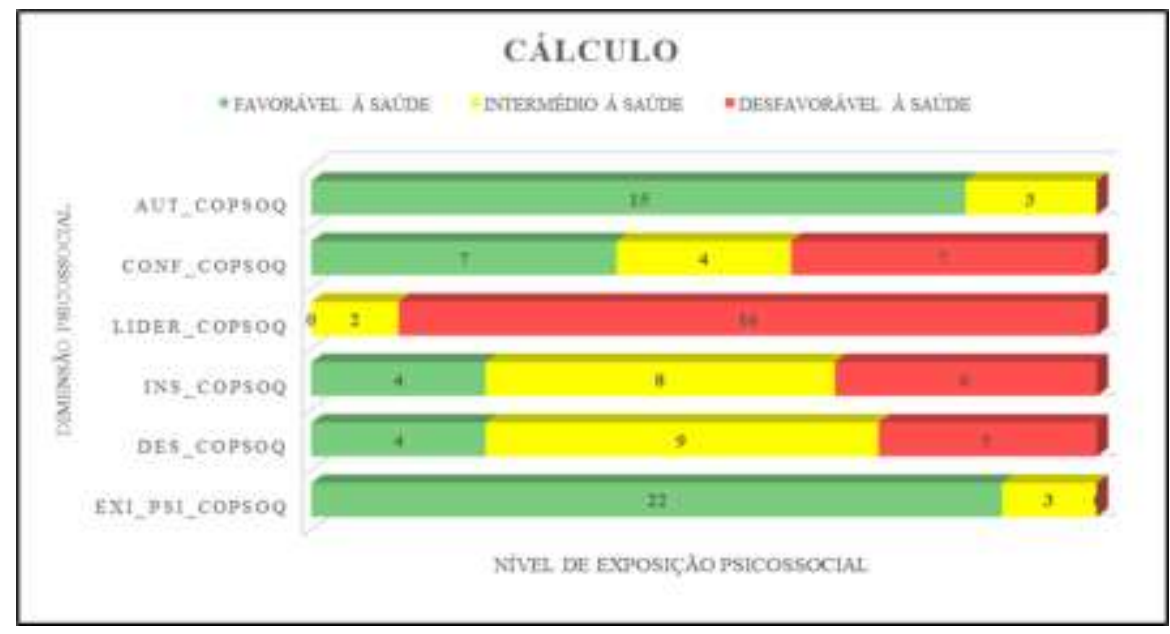

Fonte: Autores (2021).

É importante observar um nível equilibrado em relação ao conflito família/trabalho (Conf_Copsoq), insegurança (Ins_Copsoq) e ao trabalho ativo/possibilidade de desenvolvimento (Des_Copsoq), também é possível notar um nível bastante favorável à saúde nas dimensões pertinentes as exigências psicológicas (Exi_Psi_Copsq) e a autoestima (Aut_Copsoq). Porém o nível de exposição psicossocial relacionado ao apoio social e qualidade de liderança (Lider_Copsoq) é preocupante, pois apresenta um resultado bastante desfavorável à saúde.

O Gráfico 4 mostra os resultados obtidos através da pesquisa no departamento de Recurso, onde pode-se analisar por meio dos dados coletados o nível de exposição psicossocial ao qual os colaboradores estão expostos.

Gráfico 4: Nível de Exposição Psicossocial na área do Recurso.

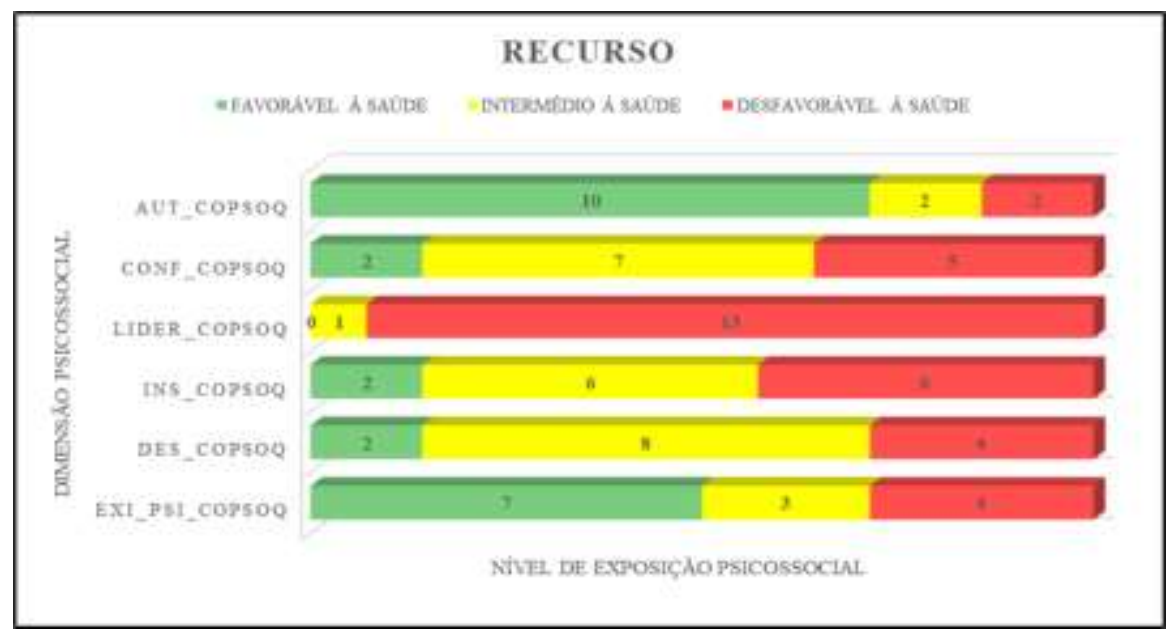

Fonte: Autores (2021).

O gráfico apresenta um nível equilibrado em relação a insegurança (Ins_Copsoq), também é possível notar um nível bastante favorável à saúde nas dimensões pertinentes a autoestima (Aut_Copsoq) e as exigências psicológicas (Exi_Psi_Copsq), os resultados mostram ainda que o conflito família/trabalho (Conf_Copsoq) e trabalho ativo/possibilidade de desenvolvimento 
(Des_Copsoq) apresentam níveis altos em intermédio à saúde. Porém o nível de exposição psicossocial relacionado ao apoio social e qualidade de liderança (Lider_Copsoq) é preocupante, pois apresenta um resultado bastante desfavorável à saúde.

No Gráfico 5 são anunciados os resultados obtidos através da pesquisa no departamento de Triagem, onde é possível analisar por meio dos dados coletados, o nível de exposição psicossocial ao qual os colaboradores estão expostos

Gráfico 5: Nível de Exposição Psicossocial na área da Triagem.

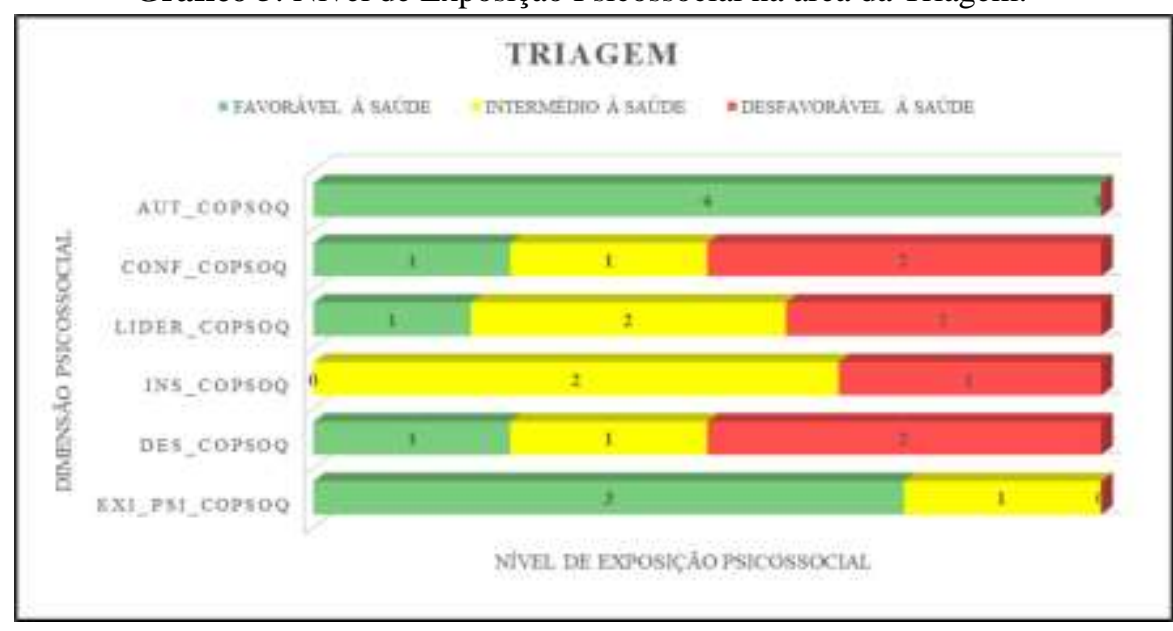

Fonte: Autores (2021).

Nele os números mostram um nível equilibrado em relação ao conflito família/trabalho (Conf_Copsoq), ao apoio social e qualidade de liderança (Lider_Copsoq) e ao trabalho ativo/possibilidade de desenvolvimento (Des_Copsoq), também é possível notar um nível bastante favorável à saúde nas dimensões pertinentes a autoestima (Aut_Copsoq) e as exigências psicológicas (Exi_Psi_Copsq), os resultados mostram ainda que a insegurança (Ins_Copsoq) apresenta nível alto no intermédio à saúde.

No Gráfico 6 são apresentados os dados coletados através da pesquisa no departamento de ADM, onde é possível observar por meio dos resultados obtidos, o nível de exposição psicossocial ao qual os colaboradores estão expostos.

Gráfico 6. Nível de Exposição Psicossocial na área de ADM,

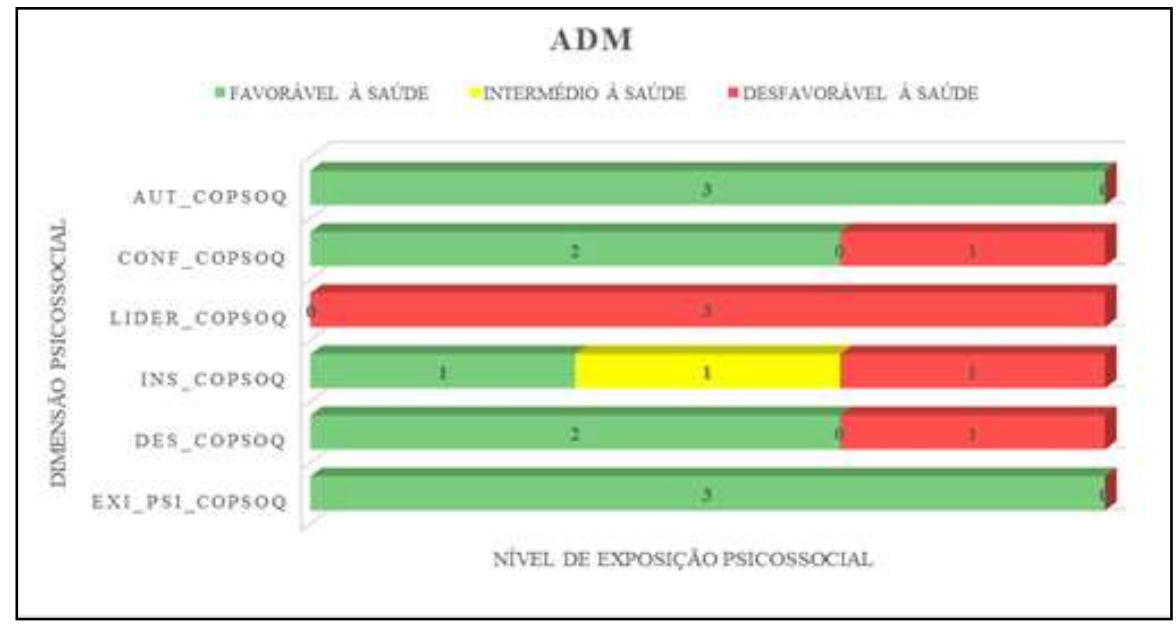

Fonte: Autores (2021).

Os resultados mostram um nível equilibrado em relação a insegurança (Ins_Copsoq), também é possível notar um nível bastante favorável à saúde nas dimensões pertinentes a autoestima (Aut_Copsoq), as exigências psicológicas (Exi_Psi_Copsq), ao conflito família/trabalho (Conf_Copsoq) e ao trabalho ativo/possibilidade de desenvolvimento (Des_Copsoq), os resultados 
mostram ainda que a insegurança (Ins_Copsoq) apresenta nível alto no intermédio à saúde. Porém o nível de exposição psicossocial relacionado ao apoio social e qualidade de liderança (Lider_Copsoq) é preocupante, pois apresenta um resultado bastante desfavorável à saúde.

Diante da análise dos dados, por meio dos gráficos estatísticos apresentados, pode-se observar que as quatro áreas dentro do setor se encontram em um nível bastante desfavorável à saúde em uma das dimensões psicossociais. Dentre as divisões avaliadas estão, as exigências psicológicas (Exi_Psi_Copsq) com quatro colaboradores, à insegurança (Ins_Copsoq) com quatorze colaboradores, ao conflito família/trabalho (Conf_Copsoq) com quinze colaboradores, a autoestima (Aut_Copsoq) com dois colaboradores e o trabalho ativo e possibilidade de desenvolvimento (Des_Copsoq) com quatro colaboradores. No entanto, o risco à saúde psicossocial relacionado ao apoio social e qualidade de liderança (Lider_Copsoq) é o problema mais comum dentre os departamentos do setor da empresa, com cerca de trinta e quatro colaboradores afetados.

\subsection{Resultado da avaliação ergonômica dos postos de trabalho}

Em análise ao Gráfico 7, é possível notar que a maioria dos colaboradores da empresa apresentam irregularidades no domínio postural, esses dados representam a quantidade de irregularidades pelo número de postos. Sendo assim, durante a inspeção, pôde -se observar inadequações relacionadas a posição dos braços, antebraços, lombar, joelhos, pés e cabeça.

Gráfico 7: Quantitativo de irregularidades no domínio postural por $\mathrm{n}^{\circ}$ de postos de trabalho.

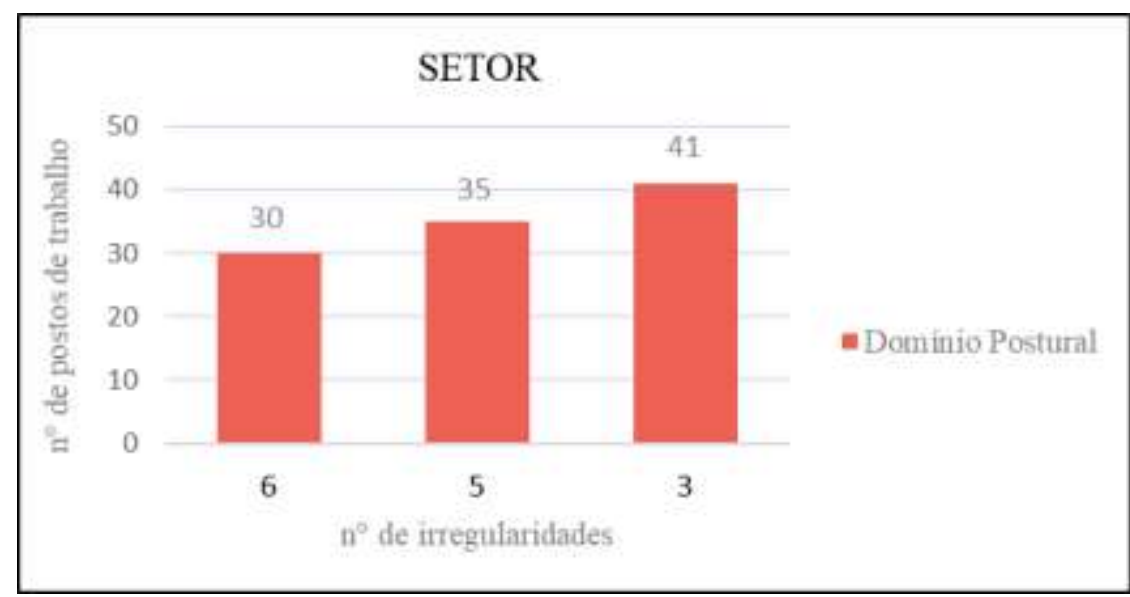

Fonte: Autores (2021).

Dessa forma, o estudo seguiu avaliando outros aspectos, como mostra o Gráfico 8, no qual os dados foram apresentados de forma quantitativa por cada tipo de irregularidade no âmbito ergonômico, levando em conta as características iguais nos cinquenta e seis postos de trabalho, dentre todas as áreas do setor. 
Gráfico 8: Quantitativo por $n^{\circ}$ de irregularidades em cada domínio no setor em geral.

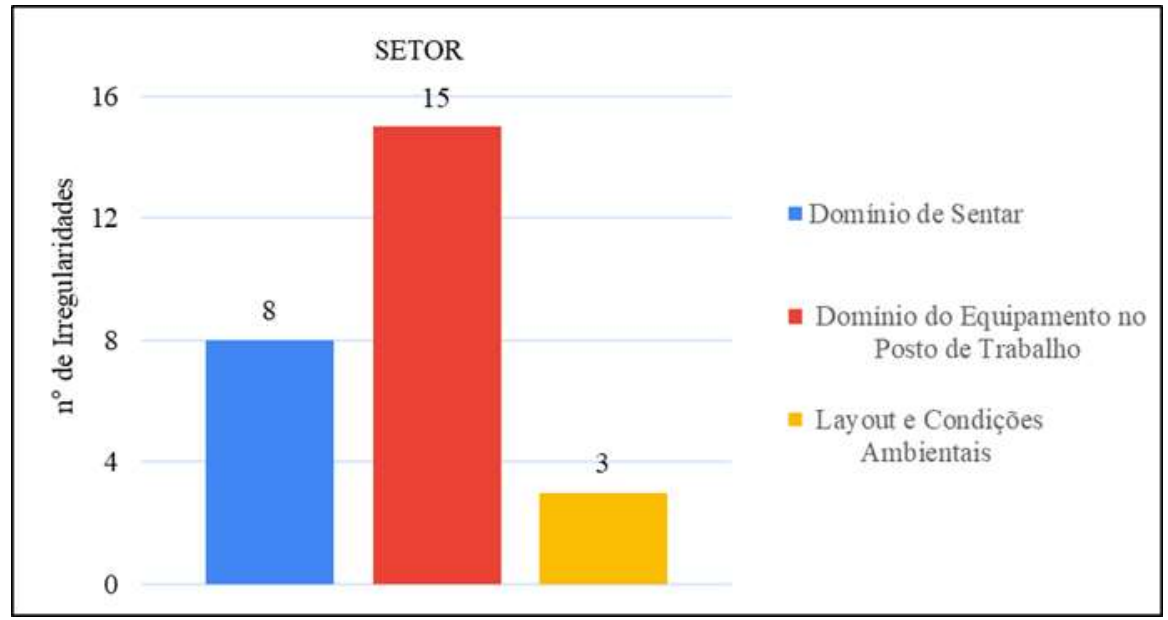

Fonte: Autores (2021).

Segundo o que mostra o gráfico acima, o domínio do equipamento no posto de trabalho foi o que se destacou com o maior número de inadequações, seguido pelo domínio de se sentar, que também apresentou muitas irregularidades relacionadas a postura física do colaborador no posto de trabalho.

\subsubsection{Inadequações encontradas}

Durante a pesquisa em campo, na qual se analisou todos os postos de trabalho, foram encontradas irregularidades das quais são descrevidas neste estudo de forma superficial, não levando em conta outras irregularidades encontradas dentro do mesmo contexto de cada uma delas, tais são as inadequações:

- Os colaboradores não receberam orientações necessárias sobre o uso adequado das cadeiras.

- Antropométricas biomecânicas e fisiológicas da pessoa não foram tidos em conta quando se escolheu a cadeira;

- O suporte do antebraço não tem superfície almofada;

- As cadeiras não possuem um encosto ajustável reclinável na qual pudesse ser ajustado em altura;

- Os postos de trabalho não possuem suporte para os pés;

- Não existe suporte para documentos;

- Os colaboradores não receberam orientações sobre a melhor forma de usar o teclado;

- Os teclados não possuem suporte para pulso;

- Os teclados não possuem apoio de antebraço;

- Os monitores não estão nivelados na mesma altura ao nível dos olhos;

- Alguns postos não possuem fontes artificiais de luz orientadas em paralelo a sua superfície de trabalho e ao monitor;

- Os colaboradores não receberam orientações sobre o uso adequado do mouse de computador.

- Os mouses de computador não são usados sobre uma esteira com designer ergonômico (apoio para o punho em gel acolchoado);

Além de todas as inadequações citadas acima, da qual precisa ser corrigida para que os trabalhadores possam exercer suas atividades de forma adequada, foi observado muitos irregularidades relacionadas a má postura. Questão essa, que envolve 
a falta de conscientização por parte dos colaboradores, e o não investimento em ideias estratégicas por meio da empresa que estimulem o bom hábito da postura correta.

\section{Propostas de Melhorias}

Diante dos resultados obtidos em estudo chegamos às seguintes sugestões de melhorias:

\section{- Palestras de conscientização}

É importante que haja palestras de conscientização que visem entregar o máximo conhecimento aos colaboradores sobre os riscos presentes em suas funções, bem como apresentar meios para melhorar a postura física nos postos de trabalho e entre outras medidas de prevenção aos riscos ocupacionais. Com isso, conseguir construir de maneira sólida uma cultura de segurança dentro do setor da empresa.

\section{- Ginástica laboral}

A implantação da ginástica laboral no ambiente de trabalho é uma boa sugestão no combate a má postura corporal e a fadiga causada por várias horas na mesma posição em frente ao computador. Seus inúmeros benefícios ajudam a reduzir o número de afastamentos caudados por problemas de saúde física e mental.

\section{- Inclusão de equipamentos ergonômicos nos postos de trabalhos}

Investir em equipamentos ergonômicos aos postos de trabalho é de total importância às atividades exercidas pelos colaboradores. Dessa forma a norma regulamentadora 17 estabelece nos artigos 17.3.4 e 17.4.2 os seguintes critérios:

Artigo 17.3.4 - Para as atividades em que os trabalhos devam ser realizados sentados, a partir da análise ergonômica do trabalho, poderá ser exigido suporte para os pés, que se adapte ao comprimento da perna do trabalhador.

Artigo 17.4.2 - Nas atividades que envolvam leitura de documentos para digitação, datilografia ou mecanografia deve:

a) ser fornecido suporte adequado para documentos que possa ser ajustado proporcionando boa postura, visualização e operação, evitando movimentação frequente do pescoço e fadiga visual;

De acordo com os resultados obtidos em análise ao ambiente de trabalho, os postos de trabalho precisam de equipamentos adequados, como:

- O suporte do antebraço com superfície almofada;

- Cadeiras com encosto ajustável reclinável na qual possa ser ajustado em altura;

- Suporte para os pés;

- Suporte para documentos;

- Suporte para pulso;

- Apoio de antebraço no teclado;

- Nivelar os monitores na mesma altura e ao nível dos olhos;

- Adequar as fontes artificiais de luz orientadas em paralelo a sua superfície de trabalho e ao monitor em alguns postos de trabalho;

- Esteira com designer ergonômico (apoio para o punho em gel acolchoado) para uso do mouse de computador. 


\section{Considerações Finais}

Diante das pesquisas realizadas neste estudo de caso, foi possível detectar o real cenário em que se encontra o ambiente de trabalho desta empresa, bem como identificar quais foram os fatores de riscos psicossociais mais afetados na vida dos colaboradores e a análise ergonômicas dos postos de trabalho.

O estudo mostrou também que apesar da falta de equipamentos adequados ao exercício das atividades no trabalho em escritório, a maioria dos trabalhadores deste setor apresentam maus hábitos de postura corporal, sendo assim, se estabelece a falta de cultura em relação a segurança e saúde por parte dos colaboradores.

Portanto, para trabalhos futuros, os autores deste estudo pretendem avançar com outros questionários, visando a elaboração de resultados para o desenvolvimento de um novo estudo apresentando as melhorias após a implantação das propostas de adequações das quais forem adotadas pela empresa.

\section{Agradecimentos}

Gostaríamos de agradecer a Deus por ter nos sustentado todos os dias até aqui, por nos conceder a capacidade de desenvolver este estudo com sucesso.

A empresa, na qual foi objeto de estudo para o desenvolvimento deste artigo, pela cordialidade em nos receber e também pela total disponibilidade em colaborar com as pesquisas, permitindo o acesso ao setor para coleta de dados.

Aos funcionários que se dispuseram a responder aos questionamentos, agradecemos a colaboração, a paciência e o entusiasmo em nos ajudar.

\section{Referências}

Abrahão, J., Sznelwar, L., Silvino, A., Sarmet, M., \& Pinho, D. (2009). Introdução à ergonomia: da prática à teoria. Editora Blucher.

Silva, C. B. (2018). Ergonomia.

Bastos, R. C., \& Bifano, A. C. S. (2017). “Estado da arte” sobre as publicações científicas envolvendo o trabalho agricola familiar no Brasil sob o ponto de vista ergonômico. Revista Engenharia na Agricultura-Reveng, 25(1), 27-37.

Brochier, A. F., Guillén, C. V., \& Galvan, T. C. Análise ergonômica do trabalho: um relato de caso na área administrativa de uma clínica integrada. Fundamentos e Práticas da Fisioterapia, 29.

Barddal, R. (2016). Raciocínio clínico e ergonomia cognitiva: uma abordagem dos erros diagnósticos a partir da teoria dos dois sistemas.

Coimbra, I. V., de Andrade, T. B. M., Iasbik, I., \& Neto, J. D. (2017). A importância da ergonomia para a saúde dos colaboradores. Anais do Seminário Científico do UNIFACIG, (1).

Corrêa, D. M. (2017). Análise ergonômica do trabalho de instrutores práticos de uma autoescola do sul de Santa Catarina: estudo de caso. Engenharia de Segurança do Trabalho-Tubarão.

Ferreira, A. S., Merino, E. A. D., \& de Figueiredo, L. F. G. (2017). Métodos utilizados na Ergonomia Organizacional: revisão de literatura. Human Factors in Design, 6(12), 058-078.

Figueiredo, L. F., \& Díaz-Merino, E. A. (2017). Ergonomia Organizacional para a identificação do estado da Casa de Massas do Rio Saltinho: por uma abordagem sistêmica. Editorial Universitat Politècnica de València.

Ferreira, L. L. (2015). Sobre a análise ergonômica do trabalho ou AET. Revista Brasileira de Saúde Ocupacional, 40(131), 8-11.

Frota, F. D. A. T. (2016). Ergonomia aplicada em trabalho com sobrecarga física na feira Manaus moderna (Doctoral dissertation).

Trabalhista, G. (2021). Norma Regulamentadora NR 17. Ergonomia. http://www.guiatrabalhista.com.br/legislacao/nr/nr17.htm

Iida, I., \& Buarque, L. I. A. (2016). Ergonomia: projeto e produção. Editora Blucher.

Lima, Tânia \& Coelho, Denis. (2011). Prevention of musculoskeletal disorders (MSDs) in office work: A case study. Work (Reading, Mass.). 39. 397-408. 10.3233/WOR-2011-1190.

Martins, J. R., Bacelar, T. C., Bonfim, W. B., Rodrigues, M. V., \& Xeres, F. C. (2017). Análise ergonômica no transporte manual de cargas: Um estudo de caso em uma empresa de produção de cimento. Revista Gestão da Produção Operações e Sistemas, 12(1), 269. 
Research, Society and Development, v. 10, n. 7, e53110716478, 2021

(CC BY 4.0) | ISSN 2525-3409 | DOI: http://dx.doi.org/10.33448/rsd-v10i7.16478

Oliveira, M. F. D. (2017). Metodologia Científica: um manual para a realização de pesquisas em administração. 2011.

Patrone Cotrim, Teresa \& Bem-haja, Pedro \& Amaral, Vânia \& Pereira, Anabela \& Silva, Carlos. (2017). Evolução do Questionário Psicossocial de Copenhaga: do COPSOQ II para o COPSOQ III. IJWC. 105-115.

Pereira, A. S., Shitsuka, D. M., Parreira, F. J., \& Shitsuka, R. (2018). Metodologia da pesquisa científica. UFSM. https://repositorio.ufsm. br/bitstream/handle/1/15824/Lic_Computacao_Metodologia-Pesquisa-Cientifica. pdf.

Quarto, L. C., Souza, S. F., Fully, F. L. T., Luquetti, E. C. F., \& de Souza Fernandes, A. (2019). Ergonomia cognitiva: uma análise das publicações por intermédio da bibliometria. Linkscienceplace-Interdisciplinary Scientific Journal, 5(4).

Silva, E. P. C. D. (2018). O uso da ergonomia na prevenção do assédio moral.

Soares, M. M. M. L., Albino Filho, M. A., Takeda, E., \& Pinheiro, O. L. (2016). < b> Percepção de professores sobre os princípios de ergonomia física nos cursos de medicina e enfermagem/Teacher's perception about the physical ergonomics principles in medicine and nursing courses. Ciência, Cuidado e Saúde, 15(3), 546-552.

Tavares, C. S. D. (2012). Ergonomia no trabalho de escritório (Doctoral dissertation).

Velasco, O. C. (2018). Ergonomia cognitiva como fator de risco em incidentes e acidentes aeronáuticos. Ciências Aeronáuticas-Unisul Virtual.

Wolf, W. F., Gomes, M. A. S., \& Tebcherani, S. M. (2020). Análise ergonômica do trabalho em uma instituição pública de ensino a distância. Revista LatinoAmericana de Inovação e Engenharia de Produção, 8(13), 67-82. 